\title{
Effect of Breed and Sex on Pork Meat Sensory Evaluation
}

\author{
Sandra Rodrigues ${ }^{1}$, Alfredo Teixeira ${ }^{2 *}$ \\ ${ }^{1}$ Mountain Research Centre (CIMO), Agrarian School of Polytechnic Institute of Bragança, Bragança, Portugal \\ ${ }^{2}$ Veterinary and Animal Research Centre (CECAV) of University of Trás-os-Montes e Alto Douro, \\ Vila Real, Portugal. \\ Email: ${ }^{*}$ teixeira@ipb.pt
}

Received 6 December 2013; revised 6 January 2014; accepted 14 January 2014

Copyright (C) 2014 by authors and Scientific Research Publishing Inc.

This work is licensed under the Creative Commons Attribution International License (CC BY). http://creativecommons.org/licenses/by/4.0/

(c) (i) Open Access

\section{Abstract}

This work had an objective to evaluate the sensory quality of two categories of pork meat from a commercial pork meat and a selected meat from the Portuguese black pork (Preto Alentejano breed). Sixteen animals were used, 8 females and 8 males from each breed. Animals had 80 - 100 $\mathrm{kg}$ of live weight. The longissimus muscle between the $5^{\text {th }}$ thoracic vertebra and the $10^{\text {th }}$ lumbar vertebra was used in the analysis. Sensory analysis was performed by a trained taste panel of 10 elements, in 5 sessions. All evaluation conditions were standardized, and the attributes studied were odor intensity, toughness, juiciness and flavor intensity. The taste panel found differences mainly between breeds. The panellists scored Preto Alentejano meat as being juicier, tenderer, and with richer taste than Commercial meat. The higher juiciness score of Preto Alentejano meat was probably attributable to the higher intramuscular fat content compared with Commercial meat. The Commercial pork was characterized mainly by high toughness.

\section{Keywords}

Pork Meat; Sensory Evaluation; Generalized Procrustes Analysis

\section{Introduction}

Pork is one of the most traditional meats consumed by Portuguese people. From the 800 thousand tons of meat and meat products produced in Portugal, pork represents about $43 \%$ of total value. In Portugal, two native pig breeds are reared (Bisara and Alentejano), according to the FAO database. Recently, there has been a development of pig’s breeds in Portugal, with many changes in production, processing and marketing taking place [1].

\footnotetext{
Corresponding author.
} 
The Preto Alentejano is a local non-improved swine breed which has survived during the last years owing to a demand increasing of Iberian products and the protection of origin designation products. Commercial pig breeds have great prolificacy and precocity which are raised purely in an intensive way, using a more advanced technology that translates into a possible improvement in terms of carcass yield.

Consumer accepts or rejects meat according to the feelings experimented when observing or ingesting it, thus evaluating food sensory quality. These sensory characteristics are perceived by senses resulting from food/consumer interaction. These perceptions will influence consumer decisions. Nevertheless, despite meat organoleptic characteristics, cooking methods can be important factors [2].

It is well known that there is variation among panelists when evaluating a sample [3]. To reduce variation it becomes necessary to develop a common language for the panelists to agree with the meaning of each term used in the evaluation of a samples set. Although it can take long time, training and discussion inside the panel are very useful to help all panelists evaluate each attribute similarly. However, no training can eliminate all variations [4]. Generalized Procrustes Analysis (GPA) [5] is a statistical method that adjusts some of the variation found. GPA is based on profiles standardization respecting to rotation/reflection, isotropic scaling and translation, in order to provide a better average which is the so called consensus configuration [3].

As referred by Dahl and Naes [6] (2004), Procrustes methods were first introduced in psychometrics, an important branch of multivariate statistical analysis. Since mid 80s, GPA has been used as a sensorial analysis standard tool, given the important contributions of Qannari et al. [7] and Wu et al. [8], among others. GPA is a multivariate technique to analyze data from various individuals, and is developed to allow food sensory analysis, where numerous judges give a score to diverse attributes of food samples. The interest is to know how individuals differ and how much they agree in their perceptions of the same object (food sample).

So the objective of this work is to study the effects of gender and breed in the sensory characterization of pork meat from a commercial and a local breed (Preto Alentejano).

\section{Materials and Methods}

The study was performed in the Laboratory of technology and quality of the carcass and meat of the Agricultural school of Bragança, using 8 females and 8 males from each of a commercial breed and the local breed Black pork (Preto Alentejano).

All animals weighted between 80 and $100 \mathrm{~kg}$ live weight. They came from two factories working in pig meat sector, one in the north and the other on the south of Portugal, both selling fresh meat and transformed products. Commercial animals were raised intensively, and fed based on commercial feed manufactured on their own factory. Alentejano animals were reared extensively, fed, almost exclusively, with acorns, complemented with fresh herbs, roots and aromatic herbs.

All animals were slaughtered at the abattoir of the factory where they came from, after 24 hours fasting, and carcasses were refrigerated at $4^{\circ} \mathrm{C}$ for 24 hours. Carcasses were carefully halved, and from the right half, the longissimus thoracis et lumborum muscle was removed between the $5^{\text {th }}$ thoracic vertebra and the $10^{\text {th }}$ lumbar vertebra. The muscle was then vacuum packed and frozen at $-21^{\circ} \mathrm{C}$ until analysis. Samples were, then, properly transported to the laboratory of technology and quality of the carcass and meat in the Agriculture School of Bragança.

To evaluate the meat quality atrained taste panel of 10 experts, in five sessions, performed a sensory analysis.

The taste panel was constituted by a group of professors and other staff of the Polytechnic Institute of Bragança, already recruited for other research studies with meat and trained specifically to taste pork meat. Training consisted in two phases. The $1^{\text {st }}$, based in an individual evaluation of muscle longissimus thoracis et lumborum samples from five different species, and the second to adapt the panel elements to scales and sensory descriptors. All training and evaluation processes obeyed the Portuguese standards [9].

Sensory evaluations were conducted in a specific tasting room of the Agriculture School of Polytechnic Institute of Bragança. During evaluations, room temperature and moisture were maintained in $20^{\circ} \mathrm{C}-22^{\circ} \mathrm{C}$ and $60 \%$ $70 \%$, respectively. Room light was white and in each booth the red light was used to mask the samples color.

Samples were taken from the muscle from the longissimus thoracis et lumborum on right side of the carcass between $10^{\text {th }}$ and $12^{\text {th }}$ lumbar vertebras. The day before the tasting session samples were thawed in a refrigerator at $4^{\circ} \mathrm{C}$. Then samples were wrapped in aluminum sheets and cooked in a conventional oven until internal temperature of $75^{\circ} \mathrm{C}$, measured by a penetration thermometer inserted in the sample center. After reaching the de- 
sired temperature, samples were cut into small pieces of $2 \times 2 \times 0.5 \mathrm{~cm}$, perpendicularly to muscular fibers, involved again in aluminum sheets and put in small heaters to maintain their temperature. Samples were presented to sensory analysis panelists in the same conditions, blind, in a random and balanced distribution order, coded with 3 digits numbers. Each panelist had enough time to evaluate each sample and between samples clean the residues left by the previous sample in their mouths with water and Golden apples or toasts.

The tasting parameters evaluated were odor intensity, toughness, and juiciness and flavor intensity.

In each session panelists evaluated 8 samples using a 10-cm non-structured scale with intervals but not numbered, representing at the extremes the minimum (sensation absence) and the maximum (extremely intense sensation). Panelists were asked to indicate a point on the scale corresponding to the intensity of their different feelings for each attribute.

The experimental design consisted of a factorial plan with 2 sexes and 2 breeds as fixed factors, comprising 4 treatments: commercial females (FC), commercial males (MC), Preto Alentejano females (FP), and Preto Alentejano males (MP). An ANOVA was performed to study the differences between treatments, and when differences were significant a Tukey test was used to evaluate those differences. Generalized Procrustes Analysis was used to minimize differences between assessors of the sensory analysis. The data matrices of 4 (meat samples) by 4 (sensory parameters) for the 10 assessors (configurations) were matched to find a consensus using the XLSTAT, an add in of Excel software.

\section{Results}

Means and standard error of the mean for all sensory traits obtained from each treatment, and the significance of the differences between means after an ANOVA are shown in Table 1. The ANOVA showed significant differences on meat hardness and juiciness. However, means are very close to each other and this can justify the use of multivariate analysis as GPA. Also in the ANOVA, no differences were found on flavor and odor, and GPA could discriminate their relation with meat samples.

Table 2 shows the PANOVA that resumes the efficiency of each GPA transformation in terms of total variation reduction. Translation was the most efficient with p-value inferior to 0.0001 .

Residuals by meat sample after transformation are identical and low (Table 3). Nevertheless, black females presented the lower residual, and for that were the most consensual among experts. On the other hand, Expert 9 had the highest residual (Table 4), and her/his evaluation did not match consensus. Two groups of experts could be grouped. The first group by experts 2, 3, 4, 7, 9 and 10 used a wider part of the scale while the second group by experts 1, 5, 6 and 8 used a narrower part of the scale, once their scaling factors were higher and lower than 1 , respectively.

Table 1. Sensory scores (means \pm SEM) for pork sensory analysis.

\begin{tabular}{cccccc}
\hline Sensory traits & FC & FP & MC & MP & $4.52 \pm 0.273$ \\
Odor intensity & $4.53 \pm 0.266$ & $5.07 \pm 0.244$ & $5.08 \pm 0.269$ & 0.219 \\
Hardness & $4.99 \pm 0.275^{\mathrm{a}}$ & $3.60 \pm 0.267^{\mathrm{b}}$ & $4.47 \pm 0.323^{\mathrm{ab}}$ & $3.50 \pm 0.274^{\mathrm{b}}$ & $<0.0001$ \\
Juiciness & $2.63 \pm 0.221^{\mathrm{b}}$ & $4.00 \pm 0.233^{\mathrm{a}}$ & $2.49 \pm 0.211^{\mathrm{b}}$ & $4.28 \pm 0.251^{\mathrm{a}}$ & $<0.0001$ \\
Flavor intensity & $4.09 \pm 0.255$ & $4.45 \pm 0.226$ & $4.24 \pm 0.238$ & $4.49 \pm 0.199$ \\
\hline
\end{tabular}

FC: Commercial female, FP: Black female, MC: Commercial male, MP: Black male. a, b: means in same row with different superscripts are significantly different.

Table 2. PANOVA for pork sensory analysis.

\begin{tabular}{|c|c|c|c|c|c|}
\hline Source & $\mathrm{DF}$ & SS & MS & $\mathrm{F}$ & $\operatorname{Pr}>F$ \\
\hline Residuals after scaling transformation & 45 & 23.777 & 0.528 & & \\
\hline Scaling transformation & 9 & 10.713 & 1.190 & 2.253 & 0.035 \\
\hline Residuals after rotation & 54 & 34.490 & 0.639 & & \\
\hline Rotation & 54 & 29.089 & 0.539 & 1.020 & 0.477 \\
\hline Residuals after translation & 108 & 63.579 & 0.589 & & \\
\hline Translation & 36 & 196.884 & 5.469 & 10.351 & $<0.0001$ \\
\hline Corrected total & 144 & 260.463 & 1.809 & & \\
\hline
\end{tabular}

DF: Degrees of freedom, SS: Sum of squares, MS: Mean squares. 
Table 3. Residual variance for each meat group for pork sensory analysis.

\begin{tabular}{cc}
\hline Meat sample $^{1}$ & Residual \\
\hline FC & 7.713 \\
FP & 4.461 \\
MC & 6.208 \\
MP & 5.395 \\
\hline
\end{tabular}

${ }^{1}$ FC: Commercial female, FP: Black female, MC: Commercial male, MP: Black male.

Table 4. Residual variance, scaling factors and percentage variation explained by the first two principal components for each assessor for pork sensory analysis.

\begin{tabular}{|c|c|c|c|c|c|}
\hline Assessor & Residual & Scaling factor & $\mathrm{F} 1$ & F2 & F3 \\
\hline 1 & 2.549 & 0.800 & 94.642 & 3.623 & 1.734 \\
\hline 2 & 2.357 & 1.609 & 33.400 & 55.642 & 10.958 \\
\hline 3 & 1.582 & 1.040 & 60.601 & 32.062 & 7.337 \\
\hline 4 & 1.298 & 2.977 & 36.549 & 34.258 & 29.193 \\
\hline 5 & 2.671 & 0.682 & 86.209 & 5.775 & 8.016 \\
\hline 6 & 2.812 & 0.784 & 60.204 & 3.770 & 36.026 \\
\hline 7 & 3.061 & 2.464 & 15.309 & 41.314 & 43.376 \\
\hline 8 & 1.501 & 0.789 & 74.107 & 22.240 & 3.653 \\
\hline 9 & 4.368 & 1.042 & 24.333 & 28.500 & 47.167 \\
\hline 10 & 1.578 & 1.229 & 59.620 & 35.807 & 4.574 \\
\hline
\end{tabular}

F1, F2, F3: Factors obtained by performing the GPA.

Three axes were sufficient to explain $100 \%$ of total variability. The first represents $59.13 \%$, the second $24.42 \%$, and the third the remaining $16.44 \%$ of the total variability.

Figure 1 represents the correlation between meat samples and Factors 1 and 2. Factor 1 (F1) has high correlations with all attributes except odor intensity. Hardness is highly and negatively correlated with F1, while juiciness, and flavor intensity are highly and positively correlated with the same factor. F1 can be called Texture. Factor 2 (F2) has low correlations with all sensory attributes, but the highest were hardness and flavor intensity.

The coordinates of meat samples show that meat from Commercial breed is placed in the negative part of F1, and meat from Black pork are placed in the positive part of the same factor. This indicates that meat from animals of different breeds is separated by texture, both hardness and juiciness, but also by flavor. On the other hand, females are in the positive part of F2, and males in the negative part. So, sexes differ in hardness and flavor intensity.

Figure 2 represents the correlation between meat samples and Factors 1 and 3. Factor 1 (F1) has high correlations with all attributes except odor intensity, as mentioned before. Factor 3 correlated highly with odor intensity and can be called Odor. Taking into account the direction of the vector representing odor, which deviates from the coordinates of meat samples, it can be said that all meat samples presented low odor intensity. However, it would be commercial males and black females' meat the ones presenting higher values of that sensory attribute.

\section{Discussion}

Sensory analysis performed by trained panelists is the most appropriate tool to explain differences between treatments as perceived by humans. However, several times the sensory evaluation of meat has been misused and preference variables are included in descriptive studies and discussed only in terms of overall acceptability. Generalized Procrustes Analysis (GPA) is a powerful multivariate technique extensively used in sensory evaluation minimizing differences between assessors, identifying agreement between them and summarizing the sets of 3-dimensional data (objects, characteristics and assessors [10]. In the present study GPA produced a consensus configuration for sensory evaluation of pork meat by the taste panel, which is more significant respecting the samples than the original non transformed mean configuration. In the analysis mean by session, by expert and by meat sample was used. Only three axes were sufficient to explain $100 \%$ of total variability. The first two axes 


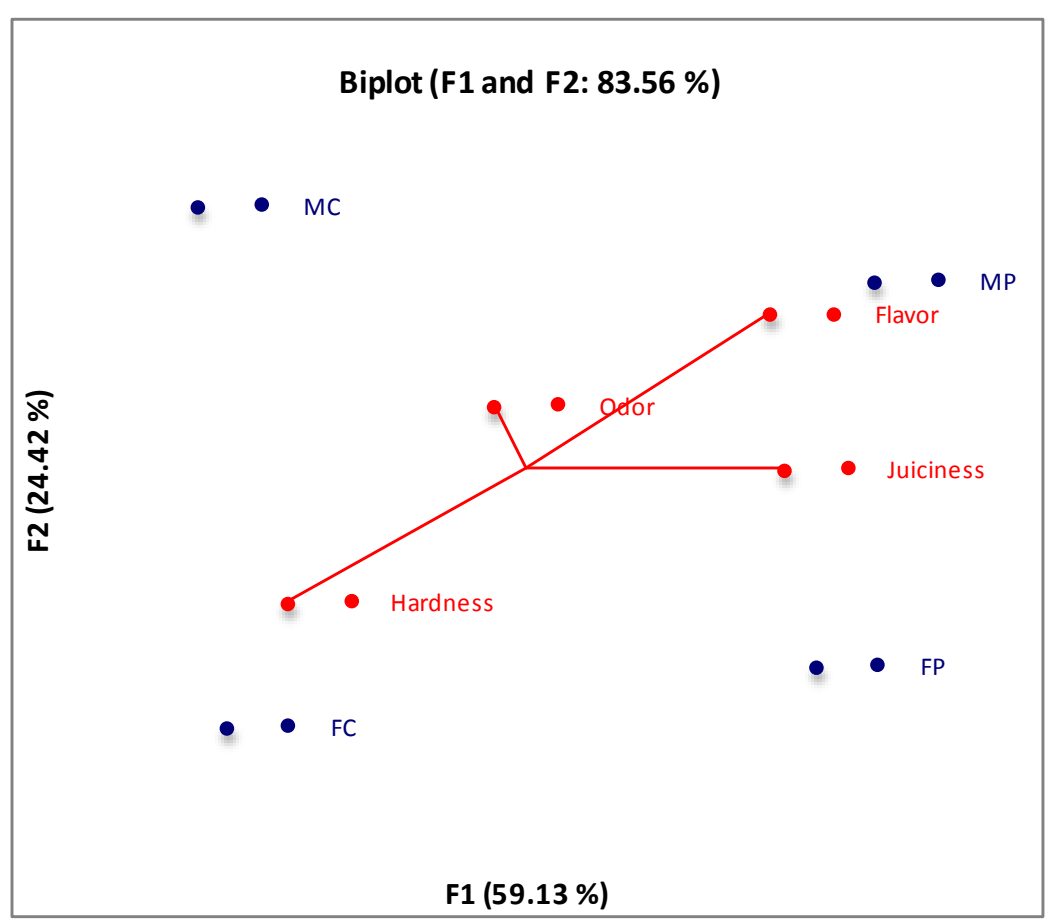

F1 first principal component of GPA; F2 second principal component of GPA.

Figure 1. Consensus configuration: joint representation of correlation between sensory traits and F1 and F2; and groups of animal's meat coordinates for pork sensory analysis.

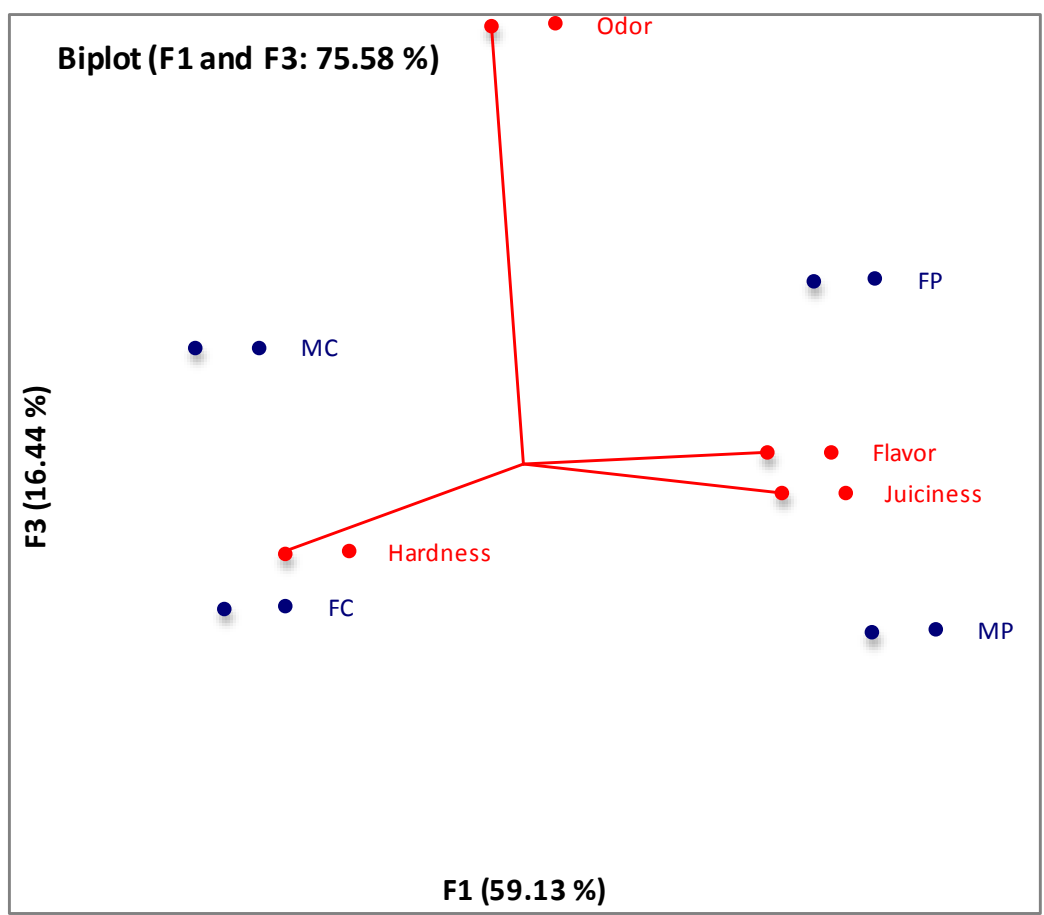

F1 first principal component of GPA; F3 third principal component of GPA.

Figure 2. Consensus configuration: joint representation of correlation between sensory traits and F1 and F3; and groups of animal's meat coordinates for pork sensory analysis. 
accounted for by $83.6 \%$ of the variability. This is an accurate result though Jonsäll et al. [11] had explained 92\% of the variability in sensory analysis of pork from different genotypes, by the first two factors in a Principal Components Analysis.

As found in the ANOVA and GPA, breed had a big effect on meat texture and Commercial breed was tougher than Black breed. Breed also had big effect on juiciness and flavor intensity, which attributes were higher in Black pork. These results are in agreement with Cameron et al. [12], comparing Duroc and British Landrace breeds; Wood et al. [13] and Edwards et al. [14] also found breed differences when evaluated texture by consumers panels, in Duroc, Landrace and Large White breeds. Lloveras et al. [15] also found breed differences on texture by a sensory panel; they verified Duroc meat was tougher than Yorkshire and Landrace meat. These findings were already reported by Persson et al. [16].

Black pork, raised outdoors, showed meat with higher juiciness and tenderness in relation to Commercial breed which contradicting the results obtained by some authors in studies also performing ANOVA and PCA (principal components analysis) by Enfaält et al. [17], working with loins from pigs reared outdoors that were less juicy and less tender than loins from pigs reared indoors; also Jonsäll et al. [18] showed that loins from pigs reared outdoors were less juicy than loins from pigs reared indoors; and as well as Jonsäll et al. [19] that found that loins of pigs from organic farm were less juicy than ones pigs reared conventionally while there was no difference in tenderness.

Results show in agreement with Cameron et al. [12] and against the popular belief that sex had lower effect on sensory attributes than breed as can be seen in Figure 2 from the high correlation of Factor 3 with odor intensity suggesting the low odor intensity in all meat samples. These results was also in accordance with Wood et al. [20], who found low level of odor intensity, and no significant differences on pork meat odor of different breeds of animals fed on different diets. Globally according Rodrigues and Teixeira [21] results confirmed that GPA analysis may be an important tool for studying relationships between products and their sensory attributes and could assist producers and retailers in finding the best products to satisfy consumer requirements.

\section{Conclusion}

Assessors were able to distinguish the different meat samples and were generally very consensual in all sensory attributes. Black pork meat had higher juiciness and flavor intensity, while commercial pork was harder and presented a little higher odor intensity. Differences found between genders were low, but males presented higher odor and flavor, and females, particularly commercial females, were harder than males.

\section{References}

[1] Matos, C.A.P. (2000) Recursos Genéticos Animais e Sistemas de Exploração Tradicionais em Portugal. Archivos de Zootecnia, 49, 363-383.

[2] Ibañez, F.C. and Barcina, Y. (2001) Análisis Sensorial de Alimentos. Métodos y Aplicaciones. Journal of Animal Science, 63, 102-113.

[3] Arnold, G.M. and Williams, A.A. (1986) The Use of Generalised Procrustes Techniques in Sensory Analysis. In: Piggot, J.R., Ed., Statistical Procedures in Food Research, Elsevier, London, 233-253.

[4] Stone, H. and Sidel, J.L. (2004) Sensory Evaluation Practices. Academic Press Inc., Tragon Corporation, Redwood City, 408 p.

[5] Gower, J.C. (1975) Generalized Procrustes Analysis. Psychometrika, 40, 33-51. http://dx.doi.org/10.1007/BF02291478

[6] Dahl, T. and Naes, T. (2004) Outlier and Group Detection in Sensory Panels Using Hierarchical Cluster Analysis with the Procrustes Distance. Food Quality and Preference, 15, 195-208. http://dx.doi.org/10.1016/S0950-3293(03)00058-2

[7] Qannari, E.M., MacFie, H.J.H. and Courcoux, P. (1999) Performance Indices and Isotropic Scaling Factors in Sensory Profiling. Food Quality and Preference, 10, 17-21. http://dx.doi.org/10.1016/S0950-3293(98)00033-0

[8] Wu, W., Guo, Q., de Jong, S. and Massart, D.L. (2002) Randomisation Test for the Number of Dimensions of the Group Average Space in Generalised Procrustes Analysis. Food Quality and Preference, 13, 191-200. http://dx.doi.org/10.1016/S0950-3293(02)00024-1

[9] NP-ISO-8586-1 (2001) Norma Portuguesa ISO 8586-1. Análise Sensorial. Guia Geral para a Selecção, Treino e Controlo dos Provadores. Parte 1: Provadores Qualificados.

[10] Rodrigues, S. and Teixeira, A. (2009) Effect of Sex and Carcass Weight on Sensory Qaulity of Goat Meat of Cabrito Trnasmontano. Journal of Animal Science, 87, 711-715. http://dx.doi.org/10.2527/jas.2007-0792 
[11] Jonsäll, A., Johansson, L., Lundström, K., Andersson, K.H., Nilsen, A.N. and Risvik, E. (2002) Effects of Genotype and Rearing System on Sensory Characteristics and Preference for Pork (M. Longissimusdorsi). Food Quality and Preference, 13, 73-80. http://dx.doi.org/10.1016/S0950-3293(01)00060-X

[12] Cameron, N.D., Warris, P.D., Porter, S.J. and Enser, M.B. (1990) Comparison of Duroc and British Landrace Pigs for Meat and Eating Quality. Meat Science, 27, 227-247. http://dx.doi.org/10.1016/0309-1740(90)90053-9

[13] Wood, J.D., Jones, R.C.D., Francombe, M.A. and Wheleham, O.P. (1986) The Effects of Fat Thickness and Sex on Pig Meat Quality with Special Reference to the Problems Associated with Over-Leanness. 2. Laboratory and Trained Taste Panel Results. Animal Production, 43, 535-544. http://dx.doi.org/10.1017/S0003356100002749

[14] Edwards, S.A. (2005) Product Quality Attributes Associated with Outdoor Pig Production. Livestock Production Science, 94, 5-14. http://dx.doi.org/10.1016/j.livprodsci.2004.11.028

[15] Lloveras, M.R., Goenaga, P.R., Irureta, M., Carduza, F., Grigione, G., Garcia, P.T. and Amendola, A. (2008) Meat Quality Traits of Comercial Hybrid Pigs in Argentina. Meat Science, 79, 458-462. http://dx.doi.org/10.1016/j.meatsci.2007.10.033

[16] Persson, J. and Stina, F.M. (1986) Carcass Properties as Related to Sensory Properties of Pork. Springer-Verlag Ibérica, Barcelona, $180 \mathrm{p}$.

[17] Enfält, A.C., Lundström, K., Hansson, I., Johansson, S. and Nyström, P.E. (1997) Comparison of Non-Carriers and Heterozygous Carriers of the RN Allele for Carcass Composition, Muscle Distribution and Technological Meat Quality in Hampshire-Sired Pigs. Livestock Production Science, 47, 221-229. http://dx.doi.org/10.1016/S0301-6226(96)01409-1

[18] Jonsäll, A., Johansson, L. and Lundström, K. (2001) Effects of Red Clover Silage and RN Genotype on Sensory Quality of Prolonged Frozen Stored Pork (M. Longissimusdorsi). Food Quality and Preference, 11, 371-376. http://dx.doi.org/10.1016/S0950-3293(00)00010-0

[19] Jonsäll, A., Johansson, L., Lundström, K., Andersson, K.H., Nilsen, A.N. and Risvik, E. (2002) Effects of Genotype and Rearing System on Sensory Characteristics and Preference for Pork (M. Longissimusdorsi). Food Quality and Preference, 13, 73-80.

[20] Wood, J.D., Nute, G.R., Richardson, R.I., Whittington, F.M., Southwood, O., Plastow, G., Mansbridge, R., da Costa, N. and Chang, K.C. (2004) Effects of Breed, Diet and Muscle on Fat Deposition and Eating Quality in Pigs. Meat Science, 67, 651-667.

[21] Rodrigues, S. and Teixeira, A. (2013) Use of Generalized Procrustes Analysis (GPA) to Test the Effects of Sex and Carcass Weight on Sensory Quality Evaluations of Terrincho Lamb Meat. Meat Science, 93, 485-488. http://dx.doi.org/10.1016/j.meatsci.2012.10.011

\section{Abbreviations}

GPA: Generalized Procrustes Analysis

PCA: Principal Components Analysis

PANOVA: Procrustes analysis of variance

F1: First principal component of GPA

F2: Second principal component of GPA

FC: Commercial females

FP: Black females

MC: Commercial males

MP: Black males

SEM: Standard error of mean

DF: Degrees of freedom

SS: Sum of squares

MS: Mean squares 